\title{
Linkage Mapping and Identification of QTLS Responsible for Earliness in Bread Wheat (Triticum aestivum $\mathrm{L}_{\text {.) }}$ in $\mathrm{F}_{2: 3}$ Mapping Population
}

\author{
N. A. Delvadiya ${ }^{1}$, D. R. Mehta $^{2}$, A. K. Nandha ${ }^{1}$ and R. R. Rathod ${ }^{1}$ \\ ${ }^{1}$ Department of Biotechnology, ${ }^{2}$ Department of Genetics and Plant Breeding, Junagadh \\ Agriculture University, Junagadh-362001, India \\ *Corresponding author
}

\begin{abstract}
A B S T R A C T
Earliness, an adaptive trait and factor of variation for agronomic characters, is a major trait in plant breeding. In present investigation, the experimental material comprised of $\mathrm{P}_{1}, \mathrm{P}_{2}$, $F_{1}, F_{2}$ and $F_{2: 3}$ generations of wheat crossDL-788-2 X GW-322 for earliness related traits with objective of linkage and QTL mapping in bread wheat. Out of 200 SSR markers screened for parental polymorphism for earliness related traits, only $11 \%$ of SSR markers showed good polymorphism between two parental lines. Out of 22 tests, all the test markers showed non-significant chi-square which revealed that observed data were agreement with expected ratio of 1:2:1 segregation ratio. The linkage map was constructed using software Ici Mapping v.4.1 and recombination frequencies were converted into map distance using Kosambi's mapping function. The markers were grouped with minimum logarithm of the odds (LOD) of 3.0 with walking speed was set at $1.0 \mathrm{cM}$. Four linkage groups with a total map length of $267.12 \mathrm{cM}$ were constructed using data from 22 marker loci for $74 \mathrm{~F}_{2}$ plants that ranged from minimum of $8.62 \mathrm{cM}$ (LG4) to maximum of 126.56 $\mathrm{cM}$ (LG1).Genotypic data of $\mathrm{F}_{2}$ and phenotypic data of on $74 \mathrm{~F}_{2: 3}$ lines were analyzed for identification of the main effect QTLs using the software ICIM-ADD mapping in QTL IciMappingV4.1. A linkage map of earliness related traits output data file was used for the construction of QTL mapping. One QTL was identified for days to 50\% flowering (LG1 at $58.0 \mathrm{cM}$, LOD 3.06, 18 PVE \%) and two QTLs for days to maturity (LG1 at $21 \mathrm{cM}$, LOD 8.89, 31.51 PVE\% and LG3 at $38 \mathrm{cM}$, LOD 12.83, 45.16 PVE\%).with use of molecular marker and QTL mapping complex from of earliness traits and their underlying genes are now far more accessible which can be routinely used by breeders in marker assisted selection in wheat breeding programs.
\end{abstract}

\section{Introduction}

The wheat belongs to the genus Triticum of the family Poaceae and its origin is believed to be Middle East Region of Asia (Lupton, 1987). Three species of wheat viz., Triticum aestivum L. (bread wheat), Triticum durum
Desf. (macaroni wheat) and Triticum dicoccum Schulb. (emmer wheat) are presently grown as commercial crop in India, covering 86,12 , and $2 \%$ of the total area, respectively(Anonymous, 2013). The bread wheat (hexaploid with chromosome number $2 n=6 x=42$ ) is cultivated in all the wheat 
growing areas of the country, the macaroni or durum wheat is mostly grown in the Northern (Punjab) and Southern states, while the emmer wheat (tetraploid, $2 \mathrm{n}=4 \mathrm{x}=28$ ) (Feldman et al., 1995; Kihara, 1944; McFadden and Sears, 1946) is confined to the Southern states (mainly Karnataka) and some parts of Gujarat.

Heading time of wheat is a complex character comprised of three genetic factors: vernalization requirement, photoperiodic response, and earliness per se. Earliness per se, different from the other two, is independent of environmental factors and is recognized as the earliness by nature which is specific to varieties. This character is controlled by several minor genes (Kato and Sawada, 2000) and they were assigned to different chromosomes. Miura and Worland (1994) reported a gene on chromosome 3A and Hoogendoorn (1985) reported genes on chromosomes 3A, 4A, 4D, 6B, and 7D. On the contrary, vernalization requirement and photoperiodic response depend on environmental factors and they ensure safer heading (reproduction) by delaying heading time until environmental condition becomes favorable. A very good understanding of, and ability to manipulate oligogenic and polygenic traits is offered to the plant breeders by recent advances in genetic marker technology (Young, 1999). A major advantage of using molecular markers for the introgression of resistance genes into cultivars is a gain in time (Tanksley et al., 1989; Melchinger, 1990) by guiding and expediting conventional plant breeding programme by reducing number of breeding cycles. The second major advantage is that it facilitates effective selection even when phenotypic selection is likely to be ineffective. The development and availability of abundant, naturally occurring, molecular markers (RFLP, RAPD, ISSR, SSRs, Isozymes, etc.) (Kochert, 1994) during the last two decades has generated renewed interest in counting, locating and measuring the effects of genes (polygenes or QTLs) controlling quantitative traits(Wu and Tanksley, 1993; Morgante and Olivieri, 1993). When there is a marker map and a segregating population for a character of interest, it is often possible to obtain information about the number, effects and positions of the QTLs affecting the trait (Paterson et al., 1988). Marker assisted selection could be more efficient than purely phenotypic selection in quite large populations and for traits showing relatively low heritabilities (Moreau et al., 1998).

The building up of a saturated linkage map using molecular markers like microsatellites (SSR) makes it possible to dissect Mendelian factors underlying a complex trait such as earliness and consequently enhance the effectiveness and accelerate the rate of breeding programmes to improve pure line varieties of self-pollinated crops and parental lines of hybrid in cross-pollinated crops. Linkage drag and confounding effects of environmental variation associated with conventional plant breeding can also be reduced. With QTL mapping, the role of specific loci can be described and interactions between genes, plant development, and environment can be analyzed. As the molecular-marker-based genetic linkage map for wheat has been constructed (William et al., 1997) and extended (Nelson et al., 2006; Ramya et al., 2010), QTL analysis is now possible utilized in molecular breeding. Earliness is an important trait in plant breeding. Its constituent traits such as flowering time and days to heading are largely controlled by vernalization genes (Vrn), photoperiod response genes (Ppd) and developmental rate genes ('earliness per se', Eps). Mapping of major genes controlling quantitative traits, flowering time (FT) and days to heading (DTH) was carried out in an intervari et al., wheat cross by Nalini et al., (2006). 


\section{Materials and Methods}

The complete set of experiment was carried out a the Biotechnology Laboratory of the Department of Genetics and Plant Breeding as well as Wheat Research Station, J.A.U., Junagadh during the year 2014 to 2017.

\section{Mapping population and phenotyping}

The experimental materials comprised two diverse parents viz., DL 788-2, and GW-322 collected from Wheat Research Station, Junagadh Agricultural University, Junagadh. The parental lineDL-788-2 has character of early maturity and parental line GW-322 has character of late maturity. The seeds of pure lines DL 788-2 and GW-322 for earliness and related traits were used as parents and sown at Wheat Research Station JAU, Junagadh during winter 2013-14. The parental lines and $\mathrm{F}_{1}$ hybrids seeds were sown during winter 2014-15 to obtain selfed seeds of $F_{2}$. Whole spikelet of $F_{1}$ plant was covered with white parchment paper bags to prevent any unwanted cross pollination. Along with parental lines and saved $F_{1}$, selfed seeds of $F_{2}$ were sown during winter 2015-16. All the necessary observations were recorded in parental lines, $F_{1 S}, F_{2 S}$. Plant leaf samples were also collected from every single plant for DNA extraction 20 days after sowing and genotyping was done. To obtain selfed seeds of $F_{3}$, whole spikelet of selected $F_{2}$ plants were covered with white parchment paper bags to prevent any unwanted crosspollination. Along with parental lines, selfed seeds of $\mathrm{F}_{3}$ were sown in two replications at Wheat Research Station, JAU, Junagadh during winter 2016-17 for $\mathrm{F}_{2: 3}$ phenotyping.

DNA isolation, polymorphism and genotyping

Total genomic DNA extraction was carried out by CTAB method as described by Stein $e t$ al.(2001) with minor modifications. To identify SSR primer pairs detecting polymorphism between parents, initial screening of parental lines was conducted before actual genotyping of individuals in segregation $F_{2}$ mapping population. For this, DNA from DL 788-2 (taken as first parent i.e. $\mathrm{P}_{1}$ ) and GW-322 (taken as second parent i.e. $\mathrm{P}_{2}$ ) and their corresponding $\mathrm{F}_{1}$ hybrids were subjected to PCR amplification with each of the available SSR primer pairs. A total of 200 SSR primers pairs were used to screen the parental polymorphism of the population. Simple Sequence Repeat (SSR) which showed good scorable polymorphic pattern in parental lines was used for characterization of $\mathrm{F}_{2}$ population. Primers required for SSR were synthesized from Merck Bioscience, Bangalore. The amplified products of SSR were analyzed on $3 \%$ agarose gel.

\section{Construction of Linkage Map}

QTL IciMapping v4.0 (Meng et al., 2015) was used for linkage group construction using all the polymorphic markers. Three general steps were involved in linkage map construction: Grouping, Ordering and Rippling. First of all, markers were grouped based on a Likelihood of odd ratio (LOD) of 3.0, recombination frequency of 0.3 and Window size $5 \mathrm{cM}$. To include additional markers on the map, Try and move to commands were used. Finally, linkage map based on SSR marker was constructed.

\section{QTL Mapping}

Trait data from $\mathrm{F}_{2: 3}$ was averaged for each entry and sorted to correspond with the progeny order of the genotypes (marker data). The total number of progeny individuals from the cross with trait and genotype information was 74. QTL mapping was performed using the Inclusive Composite Interval Mapping Additive (ICIM-ADD) method of QTL 
IciMapping v4.0. A threshold LOD score 3.0 was used to confirm significant QTL. Other parameters settings for ICIM were the largest $\mathrm{P}$-value for entering variables in stepwise regression of residual phenotype on marker variables with threshold of 0.001 for removing variables and $1 \mathrm{cM}$ walking speed along chromosome. QTL was considered to have a significant effect when LOD statistics exceeded a threshold of 3.0(Meng et al., 2015).

\section{Results and Discussion}

\section{Parental polymorphism for earliness}

The parental lines $\mathrm{P}_{1}$ (DL-788-2, early maturity) and $\mathrm{P}_{2}$ (GW-322, late maturity) were screened against 200 SSR (microsatellite) markers to identify parental polymorphic combinations. A total of 22 polymorphic SSR markers between two parental lines were used to screen the mapping population of $\mathrm{F}_{2}$ developed for earliness. Out of 200 markers screened, only $11 \%$ of SSR marker showed good polymorphism between two parental lines for traits related to earliness. All the 200 SSR makers used in the present study were previously reported and available in the public domain.

The markers consisted primary of barc (Song et al., 2005), cfd (Guyomarc'h et al., 2002), gwm (Röder et al., 1995, 1998), wmc (Gupta et al., 2002; Somers et al., 2004) markers. A total of 22 very clear and scorable polymorphic SSR markers between two parental lines (Fig. 1) were used to screen the mapping population of $\mathrm{F}_{2}$ developed for earliness.

The low level of polymorphism obtained from SSR markers in the present was akin to the results reported in rice and wheat (Chao et al., 1989; Devos et al., 1992).

\section{Segregation of markers and their distortion}

The segregation pattern of marker loci (SSR) for the mapping population of $74 \mathrm{~F}_{2}$ plants was compared with the expected ratio of 1:2:1 [1 homozygote (A) from $\mathrm{P}_{1}$ : 2 heterozygote $(\mathrm{H}): 1$ homozygote (B) from $\left.\mathrm{P}_{2}\right]$. The calculated chi-square values using observed frequency of $\mathrm{A}$ : $\mathrm{H}$ : $\mathrm{B}$ and its expected frequency for each and every individual marker locus is presented in Table 1.

The calculated chi-square values were compared with tabulated values for $5 \%$ and $1 \%$ probability levels at two degrees of freedom. Out of 22 tests for 22 SSR, all the test markers showed non-significant chisquare as expected ratios at both probability levels. This revealed that observed data were agreement with expected ones, indicating fulfillment of 1:2:1 segregation ratio.

Distorted segregation of molecular marker loci appears to be a common phenomenon in crop species (Cloutier et al., 1991; Yarnagishi et al., 1996).

\section{Construction of genetic linkage map for} earliness and related traits

The main objective of the present experiment is to develop a new intra-specific genetic linkage map DL-788-2 (early maturity) X GW-322 (late maturity) for cultivated bread wheat. The linkage map was constructed using software IciMapping v.4.1 (Meng et al., 2015).A total of 22 polymorphic markers were integrated into four linkage groups (LGs) with a total map length of $267.12 \mathrm{cM}$ which was constructed using data from 22 marker loci for $74 \mathrm{~F}_{2}$ progenies. The map lengths of individual linkage groups ranged from a minimum of $8.62 \mathrm{cM}$ (LG4) to maximum of $126.56 \mathrm{cM}$ (LG1), as shown in Fig. 2. 
A linkage map of $267.12 \mathrm{cM}$ (Kosambi) was constructed using 22 SSR markers loci spread on four linkage groups in the present study. Gorji et al., (2014) constructed a linkage map of $224 \mathrm{cM}$ from 22 well-distributed SSR markers in wheat. Wu Hong et al., (2015) constructed high-density genetic linkage map in the wheat population (Yanda $1817 \times$ Beinong) and reported genetic coverage of each chromosome which varied from $19.1 \mathrm{cM}$ to $292.9 \mathrm{cM}$ with 150 polymorphic markers in $269 \mathrm{~F}_{8}$ to $\mathrm{F}_{12}$ recombinant inbred lines (RILs) derived fromYanda1817x Beinong by single seed descent procedure.
The complete linkage map consisted of total 22 molecular markers in present investigation distributed on four linkage group with a total length of map accounted $267.12 \mathrm{cM}$. The total marker number was highest in linkage group 1 (10 loci) with total map length of this linkage group was $126.56 \mathrm{cM}$. Linkage group 4 has the lowest number of markers (2 loci) and lowest map length $(8.62 \mathrm{cM})$ in the present study. None of the polymorphic markers remained unlinked, shorter map distance was observed in present study might be due touse of only single molecular markers (SSR markers).

Table.1 Chi-square tests for 22 SSR markers used to discriminate $74 \mathrm{~F}_{2}$ equivalents to $\mathrm{P}_{1}, \mathrm{P}_{2}$, and $\mathrm{F}_{1}$

\begin{tabular}{|c|c|c|c|c|c|c|c|c|c|}
\hline $\begin{array}{l}\text { Sr. } \\
\text { No }\end{array}$ & $\begin{array}{c}\text { Marker } \\
\text { Name }\end{array}$ & Position & hmzA & htz & HmzB & $\begin{array}{l}\text { Missing } \\
\text { Marker }\end{array}$ & $\begin{array}{c}\text { Chi- } \\
\text { Square }\end{array}$ & Pr>ChiSq & $\begin{array}{c}\text { Degree of } \\
\text { Dominance }\end{array}$ \\
\hline 1 & Xgwm337 & 0.00 & 19 & 40 & 15 & 0 & 0.9189 & 0.6316 & Codominant \\
\hline 2 & Xgwm106 & 5.69 & 22 & 37 & 14 & 1 & 1.7671 & 0.4133 & Codominant \\
\hline 3 & Xgwm136 & 18.52 & 23 & 37 & 14 & 0 & 2.1892 & 0.3347 & Codominant \\
\hline 4 & Xgwm33 & 28.62 & 19 & 37 & 18 & 0 & 0.0270 & 0.9866 & Codominant \\
\hline 5 & Xgwm642 & 42.90 & 22 & 40 & 12 & 0 & 3.1892 & 0.2030 & Codominant \\
\hline 6 & GPW4431 & 60.94 & 19 & 37 & 18 & 0 & 0.0270 & 0.9866 & Codominant \\
\hline 7 & Xbarc 240 & 79.63 & 22 & 35 & 17 & 0 & 0.8919 & 0.6402 & Codominant \\
\hline 8 & Xgwm99 & 92.11 & 21 & 40 & 13 & 0 & 2.2162 & 0.3302 & Codominant \\
\hline 9 & Xgwm259 & 96.27 & 19 & 40 & 15 & 0 & 0.9189 & 0.6316 & Codominant \\
\hline 10 & Xgwm18 & 126.56 & 26 & 32 & 16 & 0 & 4.0541 & 0.1317 & Codominant \\
\hline 11 & Xgwm55.2 & 0.00 & 23 & 36 & 15 & 0 & 1.7838 & 0.4099 & Codominant \\
\hline 12 & Xgwm484 & 4.87 & 20 & 39 & 15 & 0 & 0.8919 & 0.6402 & Codominant \\
\hline 13 & Xgwm148 & 12.71 & 22 & 40 & 12 & 0 & 3.1892 & 0.2030 & Codominant \\
\hline 14 & Xgwm566 & 0.00 & 20 & 38 & 16 & 0 & 0.4865 & 0.7841 & Codominant \\
\hline 15 & Xgwm389 & 8.61 & 21 & 38 & 15 & 0 & 1.0270 & 0.5984 & Codominant \\
\hline 16 & GPW4225 & 20.41 & 21 & 36 & 17 & 0 & 0.4865 & 0.7841 & Codominant \\
\hline 17 & Xgwm162 & 37.12 & 20 & 38 & 16 & 0 & 0.4865 & 0.7841 & Codominant \\
\hline 18 & Xgwm533.1 & 59.75 & 23 & 36 & 15 & 0 & 1.7838 & 0.4099 & Codominant \\
\hline 19 & Xwmc513 & 92.33 & 25 & 32 & 17 & 0 & 3.0811 & 0.2143 & Codominant \\
\hline 20 & Xgwm583 & 119.23 & 20 & 37 & 17 & 0 & 0.2432 & 0.8855 & Codominant \\
\hline 21 & Xgwm194 & 0.00 & 18 & 42 & 14 & 0 & 1.7838 & 0.4099 & Codominant \\
\hline 22 & Xgwm608 & 8.62 & 20 & 40 & 12 & 0 & 3.1892 & 0.2030 & Codominant \\
\hline
\end{tabular}

hmzA= Homozygous for $\mathrm{P}_{1}, \mathrm{hmzB}=$ Homozygous for $\mathrm{P}_{2}$, htz=Heterozygous $\mathrm{F}_{1}$.

$*, * *$ Significant at $5 \%$ an $1 \%$ levels respectively 
Table.2 QTL identification for earliness and related traits with LOD score, PVE (\%), additive and dominance effect

\begin{tabular}{|c|c|c|c|c|c|c|c|c|c|}
\hline $\begin{array}{c}\text { Sr } \\
\text { No }\end{array}$ & Trait Name & LG & Position & $\begin{array}{c}\text { Left } \\
\text { Marker }\end{array}$ & $\begin{array}{c}\text { Right } \\
\text { Marker }\end{array}$ & LOD & $\begin{array}{c}\text { PVE } \\
(\%)\end{array}$ & Add & Dom \\
\hline $\mathbf{1}$ & $\begin{array}{c}\text { Days 50\%flowering } \\
\text { (DF) }\end{array}$ & 1 & 58.00 & Xgwm642 & GPW4431 & 3.06 & 18.7 & -2.72 & 3.48 \\
\hline $\mathbf{2}$ & $\begin{array}{c}\text { Days to } \\
\text { maturity(DTM) }\end{array}$ & 1 & 21.00 & Xgwm136 & Xgwm33 & 8.89 & 31.5 & 2.39 & 0.59 \\
\hline & 3 & 38.00 & Xgwm162 & Xgwm533 & 12.83 & 45.1 & 2.77 & 1.24 \\
\hline
\end{tabular}

Fig.1 Agarose gel from genotyping of the SSR loci (A) Xgwm 106, (B) Xgwm 259 markers differing in size of PCR-amplified DNA in individual $\mathrm{F}_{2}$ plants

(A)

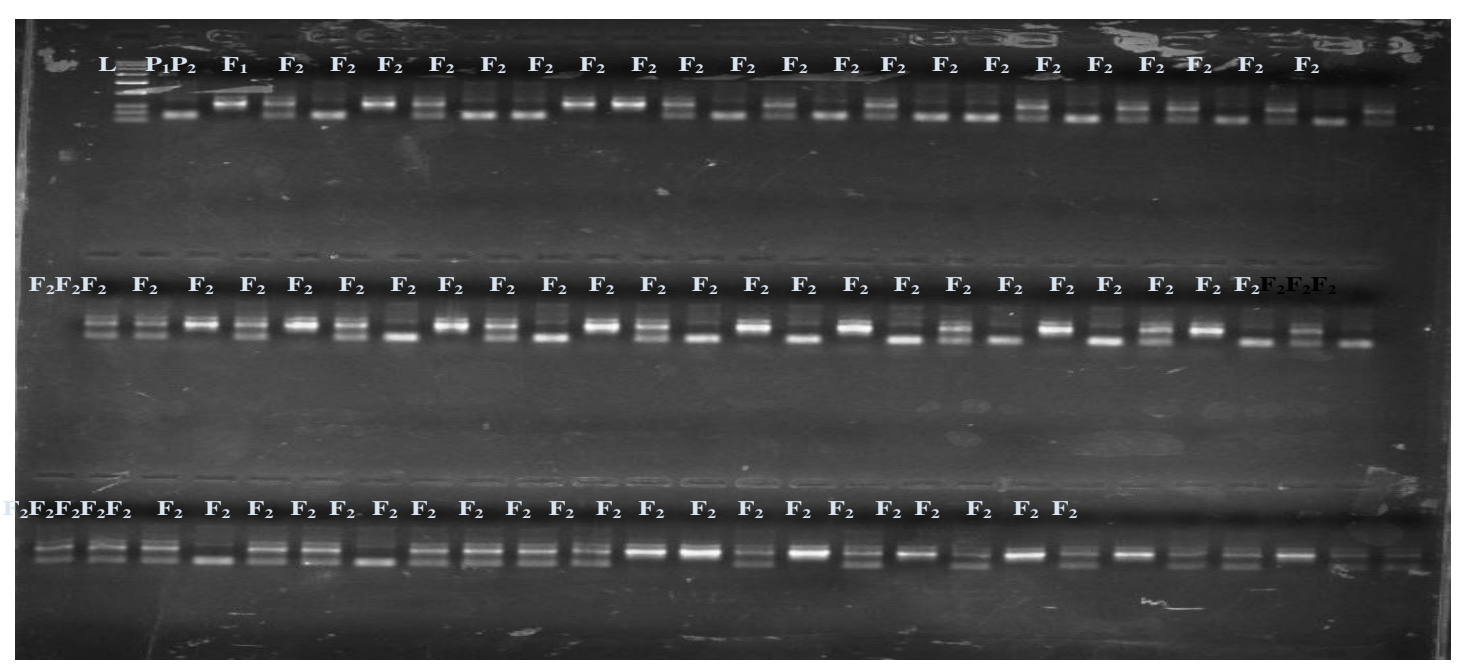

(B)

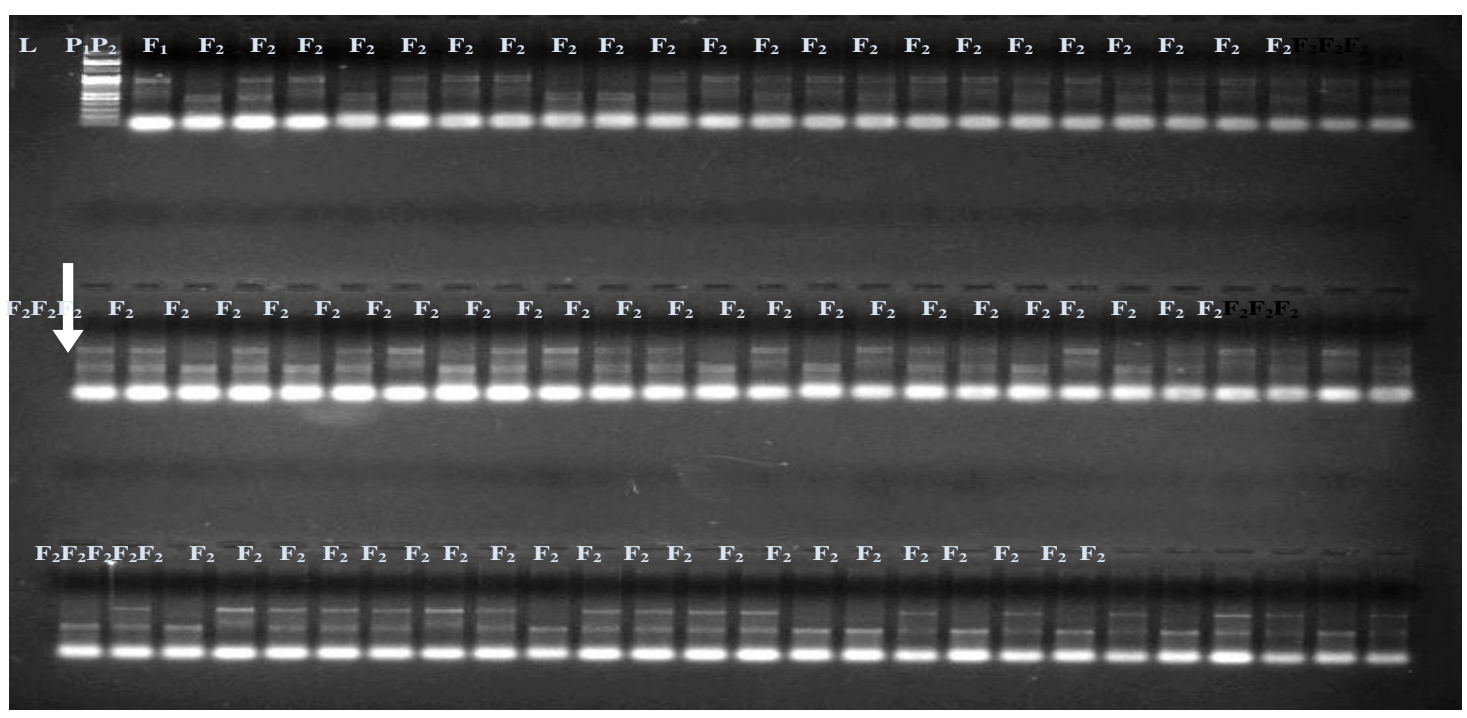


Fig.2 Genetic linkage group of bread wheat (LG-1) to (LG-4) indicates marker position on chromosome NO.1 to 4 , respectively

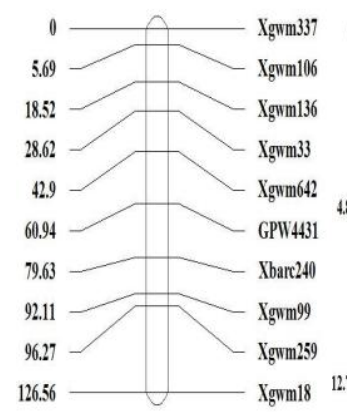

(LG-1)

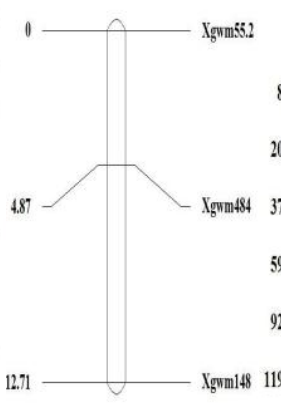

(LG-2)

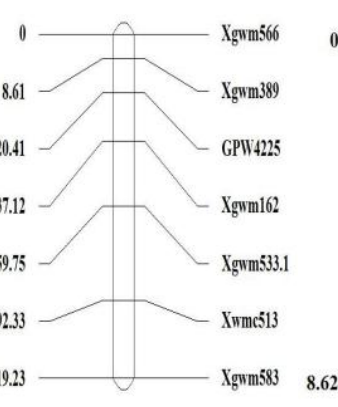

(LG-3)

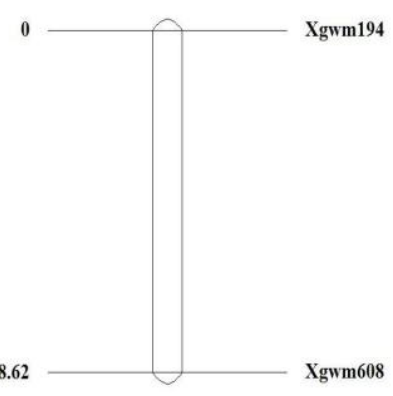

(LG-4)

Fig.3 Position of earliness and related traits in the whole genome with LOD score

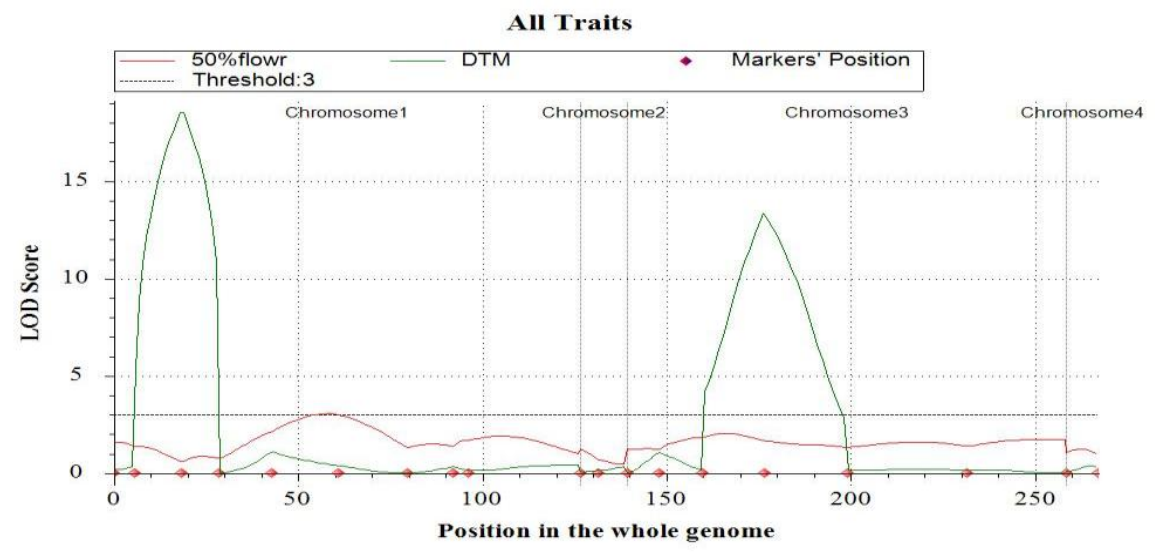

Fig.4 Position of earliness and related QTL in whole genome
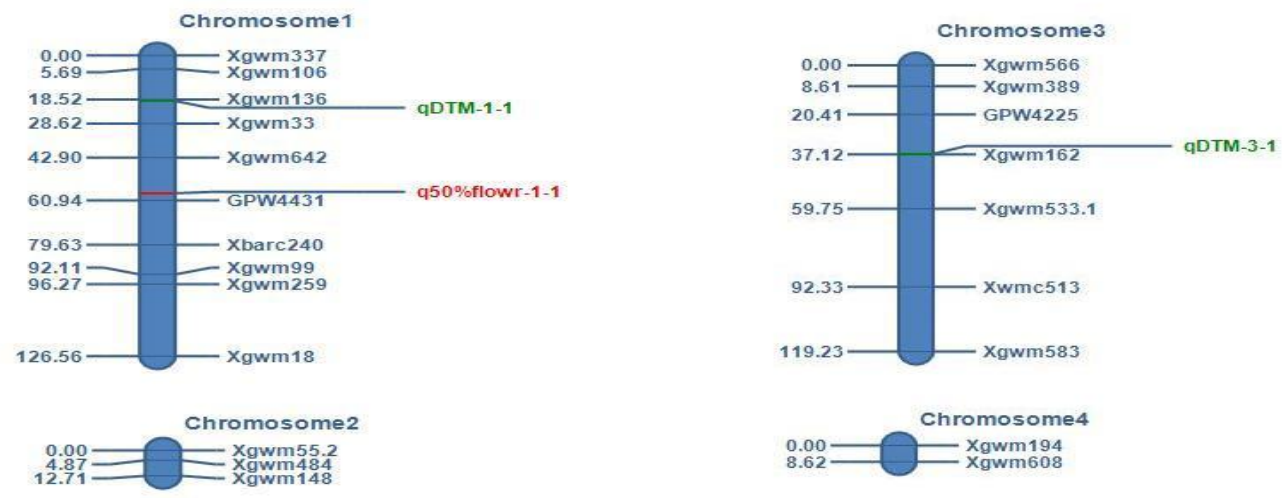
Other alternative reasons could be the sizes of the mapping populations, genetic constitution of parental lines, and number and polymorphism of marker loci obtained for both parental lines.

\section{QTL mapping for earlines and related traits}

Genotypic data of $74 \mathrm{~F}_{2}$ and phenotypic data obtained on $74 \mathrm{~F}_{2: 3}$ lines of the mapping population were analyzed for identification of the main effect QTLs using the software ICIM-ADD mapping in QTL IciMappingV4.1 (Meng et al., 2015). The $267.12 \mathrm{cM}$ linkage map constructed using Kosambi mapping function for $74 \mathrm{~F}_{2}$ progenies from the cross DL-788-2 (early maturity) x GW-322 (late maturity).QTL analysis was done for phenotypic data using day to $50 \%$ flowering and days to maturity collected from Wheat Research Station, Junagadh Agricultural University, Junagadh. QTL Ici Mapping was used for constructing linkage map was also used for QTL mapping. A linkage map output data file was used for the construction of QTL mapping. Overall, one QTL was identified (Table 2) for day to $50 \%$ flowering on chromosome 1 and two QTL for day to maturity on chromosome 1 and 3 (Fig. 3 and 4). Many previous studies were done on QTL mapping for day to $50 \%$ flowering traits which supported similar results of the present study. viz., Zou et al., (2017) identified QTL position for days to $50 \%$ flowering on chromosome 4 named as QFlt. dms-4B, QFlt. dms-4B, QFlt. dms-4B with LOD score 3.0, 2.5 and 2.5 , respectively with an additive effect of $-0.6,0.9,0.9$. Another study done by Nguyen et al., (2015) identified QTL for days to $50 \%$ flowering on chromosome 4 with LOD score of 3.6 and the additive effect of 7.18.QTL mapping for days to maturity in the present study were supported by the findings. Fatima et al., (2014) they identified two QTL named as QDPM.S.IM.wwc-2D.1 on chromosome 2 with LOD scores 8.68, the additive effect of 4.20 as well as another QTL named as QDPM.C.IM.wwc-6A.7 on chromosome 6 with LOD 4.45 score, the additive effect of 5.94 .

In conclusion the most agricultural traits of economic interest are polygenic and quantitative in nature and are controlled by many genes on the same/different chromosome. In wheat earliness is agronomically important trait. Earliness and related character is controlled by several minor genes and they were assigned to different chromosomes.QTL mapping is used to detect the genes which control the trait of interest. It is very useful for the genome-wide scan for QTLs detection in plants. Identification of marker which gives clear polymorphism, development of linkage map and detection of new QTLs associated with earliness should be useful for wheat improvement in the future, especially as these QTLs appear to have relatively large effects. Ideally QTL associated with earliness found at chromosome number 1,3 and the markers attached to the QTL after validation have the potential to be used for marker assisted selection in wheat breeding programs.

\section{References}

Anonymous, (2013). Progress report of All India Co-ordinated Wheat and Barly Improvement Project. Directorate of Wheat research, Karnal, India.

Chao, S., Sharp, P., Worland, A., Warham, E., Koebner, R. and Gale, M. (1989). RFLP-based genetic maps of wheat homoeologous group 7 chromosomes. Theor. Appl. Genet., 78: 495-504.

Cloutier, S., Landry, B.S. and Cappadocia, M. (1991). RFLP analyses of a doubled haploid population of Brassica napus. In: Proceedings $6^{\text {th }}$ Can. Soc. Plant. Mol. Biol. Ann. Meet University, Laval, 
Quebec City. p.17.

Devos, K.M. and Gale, M.D. (1992). The use of random amplified polymorphic DNA markers in wheat. Theor. Appl. Genet., 84: 567-572.

Evers, A.D., Cox, R.I., Shaheedullah, M.Z., and Withey, R.P. (1990). Predicting milling extraction rate by image analysis of wheat grains. Asp. Appl. Biol., 25: 417-426.

Fatima, S., Muhammad, A.,and Rahmatullah, Q. (2014).QTL mapping for physiological maturity in synthetic hexaploid wheat (Triticum aestivum L.) under drought stress. Pure Appl. Bio.,3(1): 25-3.

Feldman, M., Lupton, F.G.H. and Miller, T.E. (1995). Wheat s p.184-192, In Evolution of Crop Plants: J Smart, NW Simmonds (ed.).. Longmam Scientific, London.

Gorji, A.H., and Zolnoori, M. (2014). Genetic Diversity in Hexaploid Wheat Genotypes using Microsatellite Markers. Asi. J. of Biotechnology. 3:368-377.

Gupta, P., Balyan, H., Edwards, K., Isaac, P., Korzun, V., Röder, M., Gautier, M., Joudrier, P., Schlatter, A., Dubcovsky, J., De la Pena, R., Khairallah, M., Penner, G., Hayden, M., Sharp, P., Keller, B., Wang, R., Hardouin, J., Jack, P. and Leroy, P. (2002). Genetic mapping of 66 new microsatellite (SSR) loci in bread wheat. Theor. Appl. Genet., 105: 413-422.

Guyomarc'h, H., Sourdille, P., Charmet, G., Edwards, K. and Bernard, M. (2002). Characterisation of polymorphic microsatellite markers from Aegilops tauschii and transferability to the Dgenome of bread wheat. . Theor. Appl. Genet., 104: 1164-1172.

Hoogendoorn, J. (1985). A reciprocal F 1 monosomic analysis of the genetic control of the time of ear emergence, number of leaves and number of spikelets in wheat (Triticum aestivum L.). Euphytica, 34:545-558.

Kato, K., Miura, H. and Sawada, S. (2000). Mapping QTLs controlling grain yield and its components on chromosome $5 \mathrm{~A}$ of wheat. Theor. Appl. Genet.,101: 1114-1121.

Kihara, H. (1944) Discovery of the DDanalyser, one of the ancestors of Triticum vulgare. Agriculture and Horticulture, 19:13-14.

Kochert, G., (1994). RFLP Technology in Phillips, R.L and Vasil, I.K. Eds..DNA based markers in plants. pp 8-38. The Netherlands: Kluwer Academic Publishers.

Lupton, F. G. H., (1987). Wheat Breeding: Its Scientific Basis. Chapman \& Hall Ltd., London.

McFadden, E. and Sears, E. (1946). The origin of Triticum spelta and its freethreshing hexaploid relatives. $J$. of Heredity, 37: 81-89.

Melchinger, A. E. (1990). Use of molecular markers in breeding for oligogenic disease resistance. PI. Breed., 104: 119.

Meng, L., Li, H., Zhang, L. and Wang, J. (2015). QTL IciMapping: integrated software for genetic linkage map construction and quantitative trait locus mapping in bi-parental populations. Crop J. 3:265-279.

Miura, H., Worland, A.J., (1994). Genetic control of vernalization, day-length response, and earliness per se by homeologous greup-3 chromosomes in wheat. Plant Breeding, 113: 160-169.

Moreau, L., Charcosset, A., Hospital, F. and Gallais, A. (1998). Marker-assisted selection efficiency in populations of finite size. Genetics, 148: 1353-1365.

Morgante, M., and Olivieri, A.M., (1993). PCR-amplified microsatellite markers in plant genetics. Plant J., 3:175-182. 
Nalini. E., Jawali, N., Bhagwat, S.G. (2006). Analysis of QTLS for earliness components in bread wheat (Triticum aestivum L.). Founder day special issue. BARC Newsletter, 285: 183-189.

Nelson, C.J., Cristina, A., Flavio, B., Patrick, L. F., Daisy, G.G., Christine, J. B., Roberto, J. P., Marie, R.P., Perretant, M.R., Philippe, L., Calvin, O. Q., Mark E.S. (2006). Quantitative trait locus analysis of wheat quality traits. Euphytica, 149: 145-159.

Nguyen, A.T., Nishijima, R., Kajimura, T., Murai, K., and Takumi, S. (2015). Quantitative trait locus analysis for flowering-related traits using two $F_{2}$ populations derived from crosses between Japanese common wheat cultivars and synthetic hexaploids. Genes and Genetic Systems.90: 89-98.

Paterson, A. H., Lander, E., Hewitt, J. D., Peterson, S., Lincoln, S. E. and Tanksley, S. D. (1988). Resolution of quantitative traits into Mendelian factors by using a complete linkage map of restriction fragment length polymorphisms. Nature, 335: 721-726.

Pestsova, E., Ganal, M.W., Roder,and M.S. (2002c). Isolation and mapping of microsatellite markers specific for the D genome of bread wheat. Genome, 43:689-697.

Ramya, P., Chaubal, A., Kulkarni, K., Gupta, L., Kadoo, N., Dhaliwal, H.S., Chhuneja, P., Lagu, M., Gupta, V. (2010). QTL mapping of 1000-kernel weight, kernel length, and kernel width in bread wheat (Triticum aestivum L.). J. Appl. Genet., 51(4) : 421-429.

Roder, M.S., Korzun, V., Wendehake, K., Plaschke, J,. Tixer, M. H., Leroy, P. and Ganal, M.W. (1998). A Microsatellite Map of Wheat. Genetics, 149: 2007-2023.

Roder, M.S., Plaschke, J., König, S.U., Börner, A., Sorrells, M.E., Tanksley,
S.D and Ganal, M.W. (1995). Abundance variability and chromosomal location of microsatellites in wheat, Molecular Genomics Genetics, 246: 327-333.

Somers, J.D., Isaac, P., and Edwards, K. (2004). A high-density microsatellite consensus map for bread wheat (Triticum aestivum L.). Theor. Appl. Genet., 109:1105-1114.

Song, Q., Shi, J., Singh, S., Fickus, E, Costa, J., Lewis, J., Gill, B., Ward, R. and Cregan P.(2005). Development and mapping of microsatellite (SSR) markers in wheat. Theor. Appl. Genet., 110: 550-560.

Stein, N., Herren, G. and Keller, B. (2001). A new DNA extraction method for highthroughput marker analysis in a large genome species such as Triticum aestivum. Pl. Breeding, 120: 354 - 356.

Tanksley, S. D., Young, N. D., Paterson, A. H. and Bonierbale, M. W. (1989). RFLP mapping in plant breeding: New tools for an old science. Bio Technology, 7: 257-264.

William, H.M., Hoisington, D., Singh, R.P., Gonzalez-de-leon, D. (1997). Detection of quantitative trait loci associated with leaf rust resistance in bread wheat. Genome, 40: 253-260.

Wu, Q. H., Chen, Y. X., Zhou, S. H., Fu, L., Chen, J. J., Xiao, Y., Zhang, D., Ouyang, S. H., Zhao, X. J., Cui, Y., Zhang, D. Y., Liang, Y., Wang, Z. Z., Xie, J. Z., Qin, J. X., Wang, G. X., Li, D. L., Huang, Y. L., Yu, M. H., and Lu. P., (2015). High-density genetic linkage map construction and QTL mapping of grain shape and size in the wheat population Yanda1817×Beinong6. Plos One, 10: $118-144$.

WU, Z. S. and Tanksley, S.D. (1993). Abundance, Polymorphism and Genetic Mapping of Microsatellites in 
Rice. Molecular Genomics and Genetics, 241: 225-235.

Yarnagishi, M., Yano, M., Fukuta, Y., Fukui, Y., Otani, M. and Shimada, M. (1996).

Distorted segregation of RFLP markers in regenerated plants derived from anther culture of an $\mathrm{F}_{1}$ hybrid rice. Gene Genet. Syst., 71: 37- 41.

Young, N. D. (1999). A cautiously optimistic vision for marker-assisted breeding. Mol. Breed., 5: 505-510.

Zou, J., Semagn, K., Iqbal, M., Chen, H., Asif, M., and N'Diaye, A., (2017). QTLs associated with agronomic traits in the Attila $\times$ CDC Go spring wheat population evaluated under conventional management. PLOS ONE. 12(2):708-720.

\section{How to cite this article:}

Delvadiya, N. A., D. R. Mehta, A. K. Nandha and Rathod, R. R. 2020. Linkage Mapping and Identification of QTLS Responsible for Earliness in Bread Wheat (Triticum aestivum L.) in $\mathrm{F}_{2: 3}$ Mapping Population. Int.J.Curr.Microbiol.App.Sci. 9(08): 3904-3914. doi: https://doi.org/10.20546/ijcmas.2020.908.449 